\title{
Metaplastic Spinal Meningioma in the Thoracic Spine: A Case Report and Review of the Literature
}

\author{
Jae-Seong Kang ${ }^{1}$, Sung-Han $\mathrm{Oh}^{1}{ }^{1}$, Jong-Joo Lee ${ }^{1}$, Eun Mee $\mathrm{Han}^{2}$ \\ Departments of ${ }^{1}$ Neurosurgery and ${ }^{2}$ Pathology, Bundang Jesaeng Hospital, Seongnam, Republic of Korea
}

Corresponding author:

Sung-Han Oh

Department of Neurosurgery, Bundang Jesaeng

Hospital, 20, Seohyeon-ro, 180 beon-gil,

Bundang-gu, Seongnam 13590, Republic of Korea

Tel: +82-31-779-0114

Fax: +82-31-779-8095

E-mail: shoh1@dmc.or.kr

Received: June 12, 2019

Revised: August 3, 2019

Accepted: August 8, 2019

\begin{abstract}
Spinal meningiomas account for $12 \%$ of all meningiomas and are usually located in the intradural extramedullary space. Among them, spinal metaplastic meningiomas are extremely rare. This is a case report on a 59-year-old man with thoracic spinal metaplastic meningioma. This male presented with progressively worsening right leg weakness, radiating pain and paresthesia. We present a rare case of pathologically confirmed metaplastic meningioma in the thoracic spine. Additionally, we review the pathological aspects and radiographic features of spinal metaplastic meningioma.
\end{abstract}

Key Words: Meningeal neoplasms; Meningioma; Metaplasia; Thoracic vertebrae

\section{INTRODUCTION}

Meningiomas are the most common intradural extramedullary tumors, with more than $75 \%$ of them occurring in women, mainly in the thoracic spine. The diagnosis of spinal meningiomas is not very difficult based on radiologic findings and typical locations. Meningiomas are usually benign, slow-growing tumors that derive from arachnoid cap cells in the dura around the dentate ligament of the spinal cord. In most cases, they are located on the side of the spinal cord ${ }^{11)}$. The World Health Organization classifies these tumors into Grade I (benign), Grade II (atypical), and Grade III (anaplastic) meningioma. Grade I meningioma is a slowly growing tumor ${ }^{3)}$ divided into 9 subtypes:
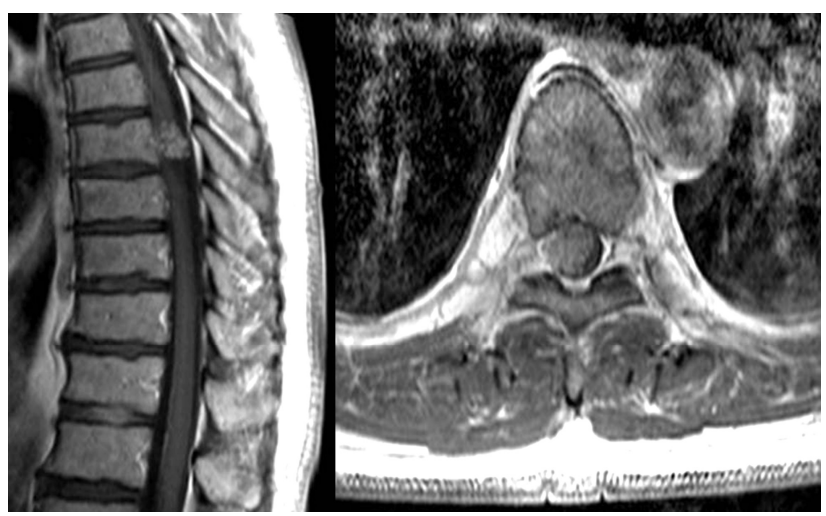

Fig. 1. Preoperative magnetic resonance images showing tumor compressed the spinal cord at the right side of T7 vertebral level. T1weighted sagittal and axial images with gadolinium enhancement. meningothelial, fibrous, transitional, psammomatous, angiomatous, microcystic, secretory, lymphoplasmacytic, and metapla$\operatorname{stic}^{14)}$. Among them, spinal metaplastic meningiomas are very rare. The metaplastic subtype is defined as a tumor containing focal or widespread mesenchymal components including osseous, cartilaginous, lipomatous, myxoid or xanthomatous tissue, singly or in combinations ${ }^{14)}$. We report a rare case of confirmed metaplastic meningioma in the thoracic spine in the male.

\section{CASE REPORT}

The study was approved by the Institutional Review Board (IRB no. DMC 2019-04-006), informed consent was not needed.

This is a study on a 59-year-old man with thoracic spinal

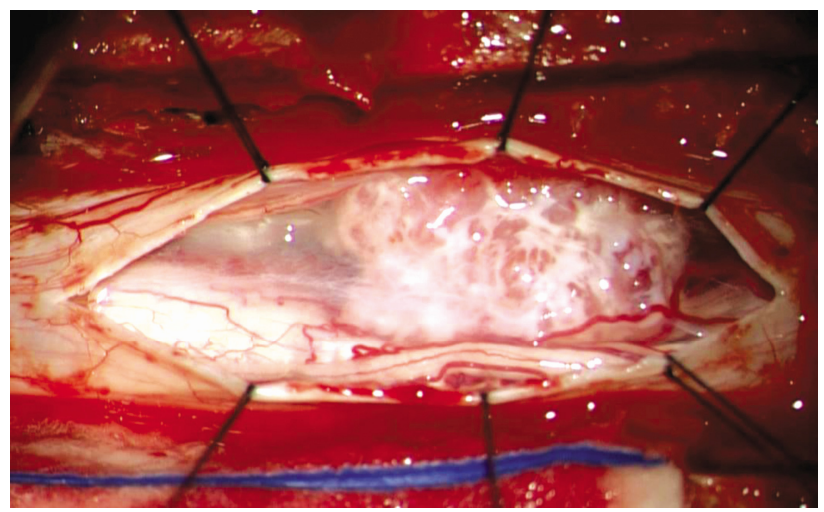

Fig. 2. Intraoperative microscopic photo revealing the intra-dural multi-lobulated calcified mass with tight adhesion to the thoracic cord and dura. Several rootlets were inserted into the mass. 

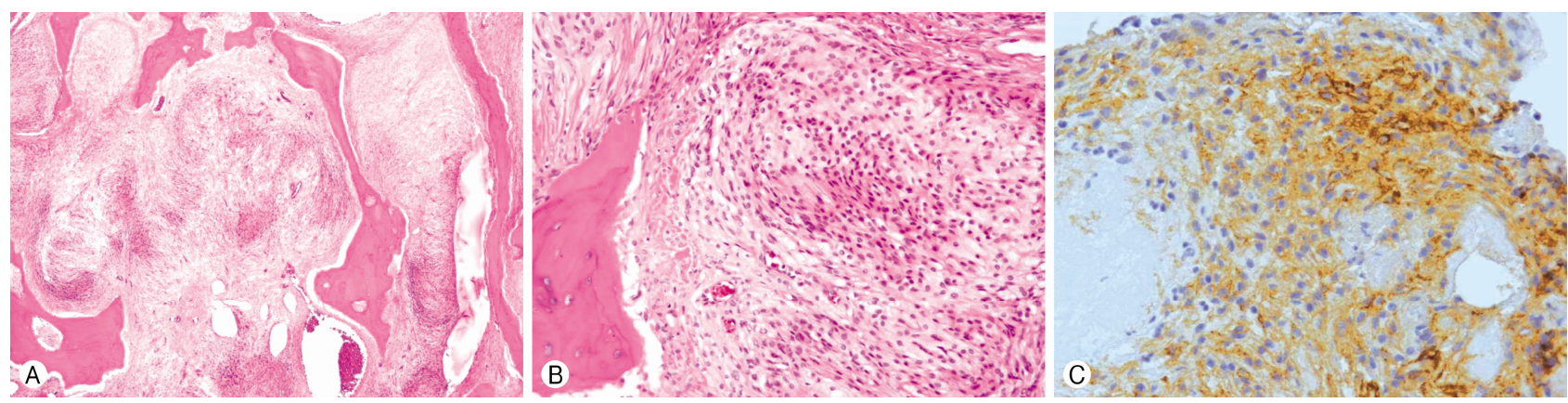

Fig. 3. Pathologic findings of the tumor. (A) The tumor consists of meningothelial component and osseous tissue (hematoxylin and eosin stain [H\&E], $\times 40$ magnification). (B) Tumor cells shows plump, elongated cells with whorl formation (H\&E, $\times 200$ magnification). (C) Immunohistochemical stain showing positive for epithelial membrane antigen ( $\times 200$ magnification).

metaplastic meningioma. The man presented with progressively worsening weakness, radiating pain and paresthesia of the right leg. On the past history he received $\mathrm{L} 4 / 5$ fusion due to spinal stenosis and he had hyperesthesia and dysesthesia on light touch and weakness GIII on the right leg. However he did not have symptoms related to bladder or anal sphincter dysfunction. On spinal magnetic resonance imaging (MRI) examination, it showed a $14 \times 11 \times 15 \mathrm{~mm}$ sized intradural extramedullary enhancing mass in the posterior epidural space of the right side at the $\mathrm{T} 7$ level. The mass caused compression of the spinal cord. T1-weighted images (WIs) with contrast enhancement showed heterogenous enhancement of the mass. The spinal mass showed intermediate signal intensity on T1and T2-WIs (Fig. 1). Lower extremity electromyography/nerve conduction velocity findings were suggestive of left lumbosacral radiculopathies.

The patient received a mass excision after laminoplasty on the T6 and T7. Microscopic examination of the intradural space mass revealed an intradural calcified multi-lobulated mass with tight adhesion to the thoracic cord and right dura. In addition, there were several rootlets inserted into the calcified tumor. The tumor was a fragment of pinkish red hard tissue with marked ossification (Fig. 2).

Histologically, the tumor consists of a meningothelial component and osseous tissue (hematoxylin and eosin [H\&E], $\times 40$ ) and the tumor cells show plump, elongated cells with whorl formations (H\&E, $\times 200)$. The immunohistochemical stain was positive for epithelial membrane antigen $(\times 200)$ and a Ki 67 antibody was applied but no positive staining was present. The final histological diagnosis was metaplastic meningioma (Fig. 3).

Immediately after surgery, his motor power was grade I of the right leg on the day of surgery. The tumor was removed, but we suspected due to nerve stretching damage after removal of a tightly attached tumor with nerve root. We administered intravenous steroid postoperatively. The next day, his motor power was recovered to Grade III, and Grade IV after active rehabilitation.

No evidence of tumor recurrence was shown on a five-month

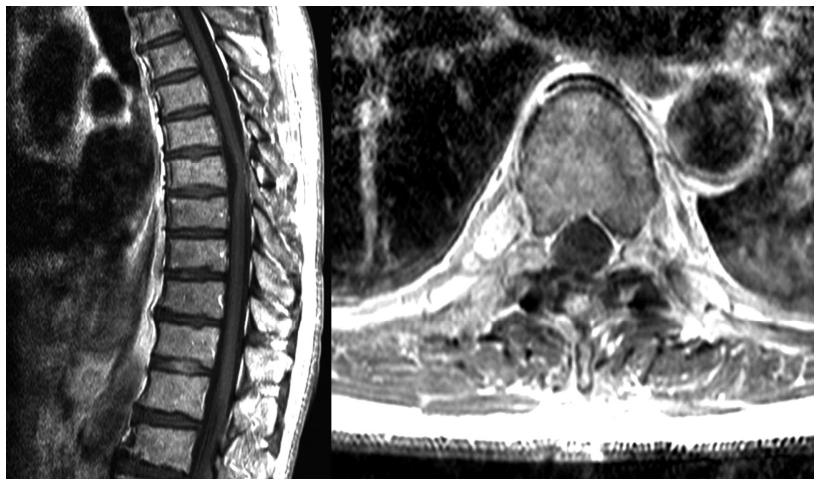

Fig. 4. Postoperative magnetic resonance images demonstrating no recurrence of tumor, but some postoperative change. $\mathrm{Tl}$-weighted sagittal and axial images with gadolinium enhancement.

follow up MRI (Fig. 4).

\section{DISCUSSION}

Spinal meningiomas represent a minority of all meningiomas, approximately $12 \%{ }^{2}$ and about $25 \%$ to $46 \%$ of total spinal cord tumors ${ }^{4,15)}$. They have a peak incidence in the sixth through eighth decades ${ }^{10)}$. These tumors most commonly involve the thoracic region (67-84\%) and are encountered least commonly in the lumbar region $(2-10 \%)^{16,17)}$. Only a small percentage of meningiomas contain ossification ${ }^{1,5)}$ and spinal osseous metaplastic meningioma is rare ${ }^{8,18)}$. There are some hypotheses as to an etiology of spinal osseous metaplastic meningioma but we do not know yet exactly the cause. The following hypotheses are the contents: (1) psammoma bodies assemble and form bone $^{1,5)}$; (2) meningioma cells turn into osteoblasts ${ }^{7}$; and (3) cells from the neural crest differentiate into osteoblasts ${ }^{6}$.

It's not easy to diagnose because of its rareness and surgery for osseous metaplastic meningioma has several difficult aspects. Adhesion of the tumor to the surrounding tissues complicates its dissection and affects the surgical outcome. In our patient, the ossified hard mass was tightly adherent to the 
normal cord and several rootlets were inserted into the tumor. So, the mass excision was very difficult from the normal cord.

Different long-term outcomes after ossified meningioma surgery have been reported. Roux et al. ${ }^{15)}$ reported 3 ossified meningiomas out of 54 spinal meningiomas and total resection in 2 cases and a subtotal resection in one case, requiring a second surgery and radiation therapy. After surgery, prognosis was good. Three of the 4 tumors reported by Levy et al. ${ }^{12)}$ as calcified had a disastrous functional outcome. Total excision of such calcified tumors should not be systematic because of a possible poor neurologic outcome if it has a very close relationship with the spinal cord itself.

Some authors believe that a resection of the dura is necessary to reduce the likelihood of recurrence. However, Klekamp and Samii ${ }^{9)}$ reported that the recurrence rate in the subset of tumors was independent of management of the dural attachment (resection and duraplasty/coagulation). We coagulated the dura surrounding the tumor.

Ohta et al. ${ }^{13)}$ reported that positive reaction of MIB antibody to Ki 67 represents the prognosis of meningioma. A positive reaction to $\mathrm{Ki} 67$ in meningiomas demonstrated recurrence. In our case, the Ki 67 antibody was negative staining. The preoperative computed tomography (CT) scan to confirm the ossification and calcification of the tumor seems necessary to evaluate surgical difficulties. Through MRI, CT, and pathology findings, the patient's postoperative course, they helped us to make a conclusive diagnosis of meningioma.

In conclusion, the patient presented several notable features including (1) rarity; (2) difficulty in surgery because of its characteristics; and (3) the negativity of the immunohistochemical study using Ki 67 antibody represents a favourable prognosis. In addition, a CT scan can give information of difficulty in surgery before the operation.

\section{CONFLICT OF INTEREST}

No potential conflict of interest relevant to this article was reported.

\section{REFERENCES}

1. Brown MH: Intraspinal meningiomas; a clinical and pathologic study. Arch Neurol 47:271-292, 1942

2. Buetow MP, Buetow PC, Smirniotopoulos JG: Typical, atypical, and misleading features in meningioma. Radiographics 11:10871106, 1991
3. Choi YH, Choi CY, Lee CH, Koo HW, Chang SH: Metaplastic meningioma overspreading the cerebral convexity. Brain Tumor Res Treat 6:97-100, 2018

4. Cohen-Gadol AA, Zikel OM, Koch CA, Scheithauer BW, Krauss WE: Spinal meningiomas in patients younger than 50 years of age: A 21-year experience. J Neurosurg 98:258-263, 2003

5. Cushing H, Eisenhardt L: Meningiomas: their classification, regional behavior, life history and surgical end result. Springfield, IL: Charles C Thomas, 1938

6. de Caro R, Giordano R, Parenti A, Zuccarello M: Osteomatous meningioma. Report of two cases. Acta Neurochir (Wien) 60:313317, 1982

7. Freedman H, Forster FM: Bone formation and destruction in hyperostoses associated with meningiomas. J Neuropathol Exp Neurol 7:69-80, 1948

8. Hirabayashi H, Takahashi J, Kato H, Ebara S, Takahashi H: Surgical resection without dural reconstruction of a lumbar meningioma in an elderly woman. Eur Spine J 18 Suppl 2:232-235, 2009

9. Klekamp J, Samii M: Surgical results for spinal meningiomas. Surg Neurol 52:552-562, 1999

10. Koeller KK, Shih RY: Intradural extramedullary spinal neoplasms: Radiologic-pathologic correlation. Radiographics 39:468490, 2019

11. Kurtoglu HS, Yavuz S, Tastekin N, Birtane M: Spinal dorsal meningioma/Spinal dorsal meningiom. Turk J Phys Med Rehabil 60:345-347, 2014

12. Levy WJ, Jr., Bay J, Dohn D: Spinal cord meningioma. J Neurosurg 57:804-812, 1982

13. Ohta M, Iwaki T, Kitamoto T, Takeshita I, Tateishi J, Fukui M: MIB1 staining index and scoring of histologic features in meningioma. Indicators for the prediction of biologic potential and postoperative management. Cancer 74:3176-3189, 1994

14. Perry A, Louis DN, Budka H, von Deimling A, Sahm F, Rushing EJ, et al.: Meningiomas. In: Louis DN, Ohgaki H, Wiestler OD, Cavenee WK eds. WHO classification of tumours of the central nervous system, ed 4th. Lyon, FR: IARC, 2016, pp231-245

15. Roux FX, Nataf F, Pinaudeau M, Borne G, Devaux B, Meder JF: Intraspinal meningiomas: review of 54 cases with discussion of poor prognosis factors and modern therapeutic management. Surg Neurol 46:458-463; discussion 463-454, 1996

16. Sahni D, Harrop JS, Kalfas IH, Vaccaro AR, Weingarten D: Exophytic intramedullary meningioma of the cervical spinal cord. J Clin Neurosci 15:1176-1179, 2008

17. Salehpour F, Zeinali A, Vahedi P, Halimi M: A rare case of intramedullary cervical spinal cord meningioma and review of the literature. Spinal Cord 46:648-650, 2008

18. Uchida K, Nakajima H, Yayama T, Sato R, Kobayashi S, Mwaka $\mathrm{ES}$, et al.: Immunohistochemical findings of multiple ossified en plaque meningiomas in the thoracic spine. J Clin Neurosci 16: 1660-1662, 2009 